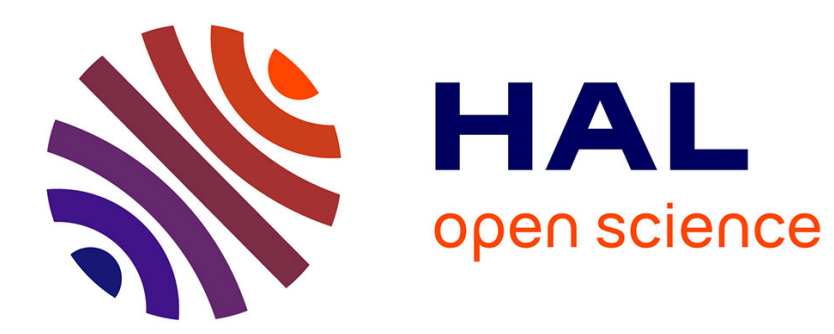

\title{
Dislocation core effects in plasticity
}

P. Veyssière

\section{To cite this version:}

P. Veyssière. Dislocation core effects in plasticity. Revue de Physique Appliquée, 1988, 23 (4), pp.431443. 10.1051/rphysap:01988002304043100 . jpa-00245791

\section{HAL Id: jpa-00245791 https://hal.science/jpa-00245791}

Submitted on 1 Jan 1988

HAL is a multi-disciplinary open access archive for the deposit and dissemination of scientific research documents, whether they are published or not. The documents may come from teaching and research institutions in France or abroad, or from public or private research centers.
L'archive ouverte pluridisciplinaire HAL, est destinée au dépôt et à la diffusion de documents scientifiques de niveau recherche, publiés ou non, émanant des établissements d'enseignement et de recherche français ou étrangers, des laboratoires publics ou privés. 
Classification

Physics Abstracts

$61.70 \mathrm{G}-61.70 \mathrm{~J}-61.70 \mathrm{~L}-61.70 \mathrm{P}$

\title{
Dislocation core effects in plasticity
}

\author{
P. Veyssière
}

Laboratoire de Métallurgie Physique, UA CNRS 131, 40 Avenue du Recteur Pineau, 86022 Poitiers Cedex, France and CNRS ONERA, B.P. 72, 92322 Châtillon Cedex, France

(Reçu le 15 juin 1987, accepté le 11 janvier 1988)

\begin{abstract}
Resume. - Cette revue fait une synthèse de travaux relatifs aux mécanismes élémentaires de la plasticité. Elle couvre des effets intrinsèques aux dislocations dans une gamme, elargie aux non-métaux, de matériaux monophasés chimiquement stables. Elle illustre l'idée selon laquelle la grande majorité des comportements observés traduit l'importance des effets de cœur de dislocations.

Abstract. - An attempt at reviewing the present knowledge of dislocation intrinsic mobility in single phase chemically stable crystals is made. Metals as well as non-metals are considered. It is show that plasticity of materials is in general dominated by dislocation core effects.
\end{abstract}

\section{Introduction.}

Provided a crystal contains a sufficient density of dislocations, it is their mobility that governs both the level of stress at which a sample commences plastic flow and the rate of work-hardening. Hence, in a study of the plastic properties of a given category of materials, it is essential to define and to classify the obstacles which oppose dislocation motion throughout the successive stages of deformation. These obstacles may be either intrinsic or extrinsic to the mobile dislocations. In the present contribution we will focus on the question of intrinsic obstacles, i.e. obstacles which originate from the crystal structure itself as opposed to barriers arising from interactions with other dislocations, with hardening particles and with precipitates and segregation zones. The specific role played by intrinsic obstacles is thus best reflected by the study of dislocation mobility in the early stages of deformation of chemically stable single phase materials. Macroscopically, this is the most clearly manifested in the critical resolved shear stress (CRSS) measured at constant strain-rate or, equivalently, by the stress at which plastic flow initiates significantly in combination with the crystallography of slip.

In three major review papers on dislocations [1-3], the nature of dislocation cores has been addressed with particular reference made to its general relevance to mechanisms of plasticity. Referring to several detailed studies of slip, Escaig [1], and later Vitek [2], have pointed out that not only does the fine structure of dislocations control the flow stress in bcc crystals at low temperature, but it also dominates in determining the flow stress dependence on temperature, strain-rate and/or orientation in a number of metallic as well as non-metallic materials. This property, termed "dislocation core effect" by Vitek [2] and Duesbery [3] is encountered in crystals where these dislocations whose mobilities govern plastic flow, are spread provided spreading is not totally contained in the glide plane.
This review will cover experimental and theoretical aspects of dislocation core effects in metallic and nonmetallic materials. Discussion will, however, concentrate on observations at the dislocation scale because of the amount of literature already devoted to macroscopic aspects and computer simulations [2-7]. The category of properties covered by the concept of core effects needs to be presented and this will be done in section 2 . Section 3 will give a view of the different natures of sessile dislocation cores with emphasis made on the distinction between glide and climb spreading. Section 4 will illustrate the situation where dislocation cores are spontaneously sessile as opposed to the case where the core transition from glissile to sessile is thermally-aided, which will be treated in section 5 . Because of the restricted amount of information available on the strainrate sensitivity of the flow stress when the flow stress behaves anomalously, this topic will only be briefly addressed in section 6 .

\section{Generalities on core effects.}

In his voluminous review article, largely devoted to bcc and to a lesser extent to close-packed crystals, Duesbery [3] supplemented the statement on the generality of dislocation core effects $[1,2]$ and showed that they give rise to several typical macroscopic signals. What indicates that core effects play a role during deformation is the occurrence of one or both of the following two features : a marked temperature dependence of the flow stress and a violation of the Schmid law. The latter implies in fact that the CRSS on a given slip system depends on orientation and/or is influenced by $a$ non-glide component of the applied stress. Based on our present knowledge of the plasticity of metallic materials. there are no established counterexamples to these criteria.

There remains, however, a class of plastic behaviour for which core effects are regarded as of secondary importance : the case of glide on the dense planes in 
close-packed materials as for instance basal slip in Cd, $\mathrm{Zn}, \mathrm{Mg}$, Co and Be, stage $I$ of $<110>(111)$ slip in fcc crystals or, to a lesser extent, of $\langle 110\rangle(110)$ slip in halkali halides with the rocksalt structure. Although representative of a relatively narrow variety of materials, it is the most documented of plastic processes; this is essentially due to the fortuitous availability a few decades ago of suitable single crystals $[2,3]$. For these core-insensitive situations, given the orientation of the applied stress $\sigma$, the CRSS is essentially independent of temperature when normalized to the elastic modulus (figure 1). In addition, given the temperature, the CRSS remains constant whatever the orientation and the sense of the external stress At the dislocation scale, this behaviour is related to more or less extended bidimensional configurations that are confined to their slip plane. The core structure is then important in determining the geometry of slip. As it glides, the (partial) dislocation line is still subject to the periodicity of the crystal, but the resulting leve! of Peierls friction stress is generally very low and essentially obliterated by thermal vibrations; low temperature experiments have been, however, successfully carried out to identify the Peierls barrier in fcc metals (see for instance [8]) as well as in $\mathrm{NaCl}$ [9-11].

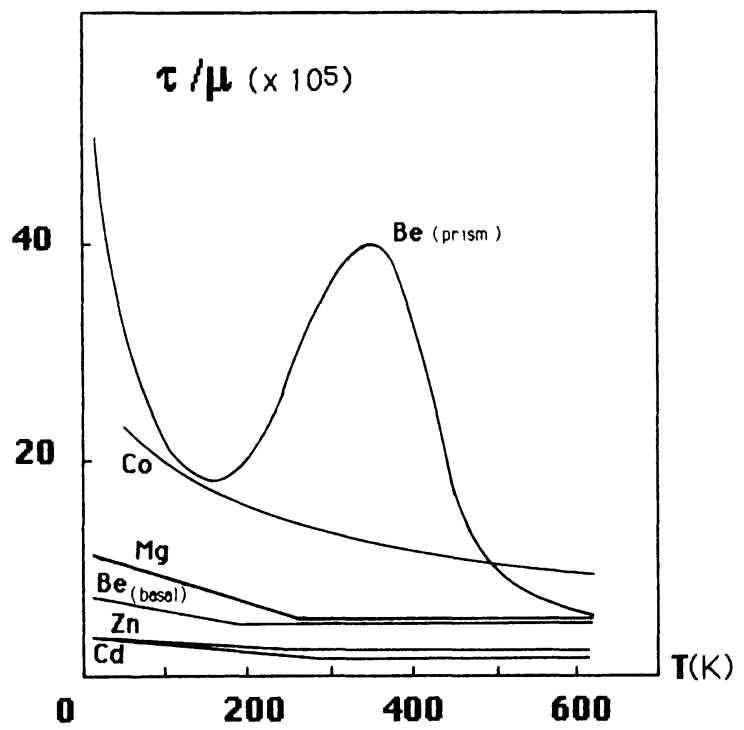

Fig. 1. - Plot of the normalized CRSS $(\tau)$ of $\mathrm{Cd}, \mathrm{Zn}, \mathrm{Be}, \mathrm{Mg}$ and Co deformed on the basal plane together with that of Be on the prismatic plane (after [45]). Note that the CRSS decreases by a factor of 2 over the whole range of temperature for the former group, whereas there is one order of magnitude between the high temperature CRSS of $\mathrm{Be}$ (prism.) and its value at $\mathrm{OK}$.

With the notion of core effects broadened to include dislocation splitting, there is in fact no instance where these would play no role in plasticity, since the core effects are then manifested also by the property that glide is confined to those planes on which planar spreading is structurally favoured $[1,3]$. Within such an interpretation, the concept of core effects turns out to lose most of its physical interest, since it does not allow for a critical discrimination between the regular behaviour of primary glide in close-packed planes and the wide variety of specific behaviours whose analyses require in each case that the core structure be well understood.

Following Vitek [2] and Duesbery [3], we will thus classify as core effects only those situations where a dislocation shows some tendency towards spreading out of its primary glide plane, independent of the magnitude of this effect.

The notion of core effects refer then more to deforma- tion mechanisms than to the crystallography of slip. It covers for instance mechanisms as distinct as the motion of screw dislocations in bcc crystals and cross-slip in the fcc structure. In the former class of materials, spreading is indeed essentially confined to a few interatomic distances, whereas it can extend in the latter case over a wider range, named the dissociation width, that is much larger than the magnitude of the Burgers vector.

\section{Core-controlled mobility.}

Perfect dislocations tend to minimize their total energy by spreading in several alternative ways, characteristic of the crystal structure, that may either enhance or greatly reduce their mobility. Dislocation spreading does not always require the existence of stacking faults bounded by regular partial dislocations as, for instance, in fcc crystals. Generalised unstable faults bordered by fractional dislocations may instead explain the properties of dislocation cores [12]. With reference to further motion in the initial slip plane, the possible core configurations are either "glissile" or "sessile" depending, respectively, upon whether they are fully confined in the dislocation glide plane or not. Dislocation motion may proceed either by glide or by climb and this holds true for the dislocation mechanisms involved in core spreading (figure 2).

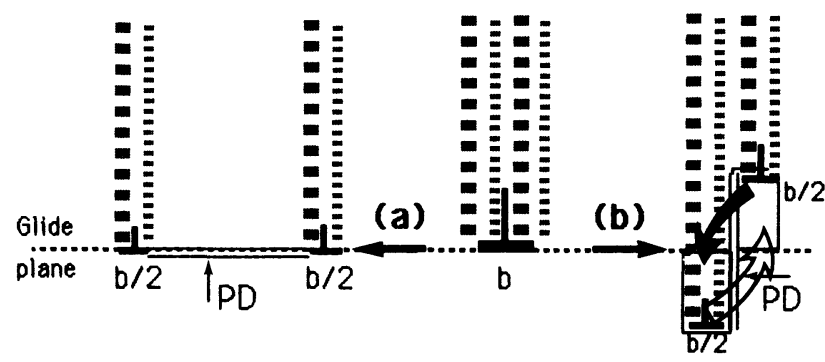

Fig. 2. - Dissociation of a perfect dislocation, (a) by glide in the glide plane, (b) by climb perpendicular to the glide plane; in the latter case, it is shown schematically that the dissociation process can be self-fed (PD : planar defect in the atomic sequence, i.e. stacking fault or antiphase boundary).

Sessile spreading into partial or fractional dislocations may occur by glide of screw dislocations such that :

- more than two non-coplanar members are formed This is the case of bcc crystals where the screws have a $1 / 2<111>$ Burgers vector and exhibit a slightly extended core with threefold symmetry (figure $3 a,[13]$ ). On the other hand, the dislocation cores in the $\mathrm{L}_{2}$ and $\mathrm{L} 1_{0}$ ordered structures are much more extended because of a low energy, metastable antiphase boundary, but they show essentially the same manifold complexity (figures $3 \mathrm{~b}$ and $3 \mathrm{c},[2,14-16])$. Very analogous is the fine structure of Lomer-Cottrell locks in fcc alloys $[1,17]$ as well as that of dislocations whose Burgers vector contains a component along the $c$ axis, in $\alpha$-sulphur [18]. 


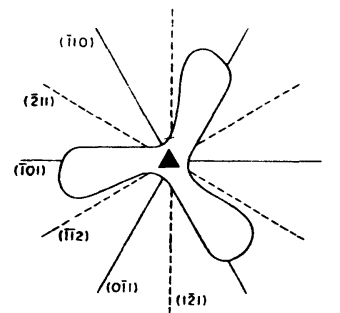

(a)

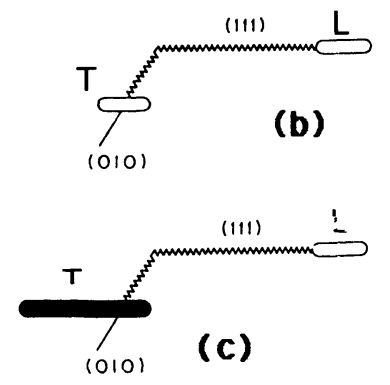

Fig. 3. - Possible sessile core symmetries resulting from glide. a) core of the $1 / 2[111]$ screw in a bcc crystal (after [2]), b) core of a superdislocation with [101] Burgers vector in the $\mathrm{L}_{2}$ structure, the extension of each superpartial into two Shockleys in the (111) primary glide plane is schematically drawn (after [2]), of same as in fig. $3 \mathrm{~b}$ for the $\mathrm{L}_{0} 0$ structure : the dissociation of one of the two superpartials gives rise to a low energy stacking fault (drawn in black). ( $L$ : leading, $T$ : trailing partial).

- the splitting plane is not the primary alide plane. This is a situation which is well represented in closepacked materials, as for instance through cross-slip of screw dislocations and non-compact slip in fcc crystals or in the case of prismatic glide in some hcp alloys (see sections 4.1 and 5.1 , see also [19]).

Sessile spreading may as well occur by climb at nonscrew dislocation segments (figure $2 b$ ), but only little work has been done so far in this area (section 5.2).

As far as the macroscopic signature of a core-controlled plastic behaviour is concerned, the most important contribution originates from the nature of the glissile to sessile (G-S) and/or sessile to glissile (S-G) transformations. Indeed, according to whether the core has adopted its extended configuration spontaneously $(54)$ or with the help of thermal vibration ( 5 5), various regimes for the flow stress dependence with temperature can be expected. These are discussed in the next two sections.

\section{Athermal G-S transition.}

In this situation, there is no energetic obstacle to the transition from the glissile to the sessile core. The latter state is then adopted spontaneously as the dislocation line meets the appropriate Peierls valley. Long screws are consistently observed to dominate within the microstructure, thus reflecting the dislocation character with lowest mobility. The flow stress shows a negative dependence upon temperature because the friction that the lattice opposes to slip of the sessile screws is overcome by the thermally-aided formation and propagation of kink pair (double kinks). This is well embodied by the low temperature variation of the flow stress in bcc crystals which, because it has already been the subject of a number of comprehensive reviews [27,20 ], will not be re-emphasised here. Similarly, since some (bcc-based) B2 ordered alloys exhibit a flow stress peak at intermediate temperature, which adds to a marked sensitivity at low temperature, their case will be examined in $\$ 5.1$. In the present section, we will instead concentrate on several instances of non-compact slip in some other structures.

4.1 H.C.P. CRYSTALS. - The strong thermal dependence of the CRSS in prismatic slip is a regular feature in hcp crystals. Little is known of the CRSS of first- and secondorder pyramidal slip systems. As far as the latter slip system is concerned, a marked thermal sensitivity has been measured in $\mathrm{Mg}$ at low temperature [21], but it is agreed in this case that dislocation cores should be complex both in the screw and in the edge orientations, both of which may be rate-controlling $[2,3]$. Prismatic and first-order pyramidal slip are potential cross-slip systems for basal slip (and vice versa) and the spreading of screw dislocations will determine the characteristics of deformation. The situation where spreading is confined to the basal plane has been briefly discussed in section 2 (figure 1). When basal spreading is not spontaneously favoured, the CRSS is strongly thermally-activated and the critical shear stress resolved on the basal plane may not be the lowest (figure 4). Legrand [22] has shown that the choice of the easy glide system in hcp crystals depends essentially upon the electronic structure of these. By use of pseudopotentials and of a tight binding method in normal and transition metals, respectively, he has been able to establish an excellent correlation between the observed glide system and the ratio between the stacking fault energies in the basal and in the prismatic planes. In addition, the atomistic simulations performed in the case of titanium indicate that the core structure of a screw dislocation, which is consistently extended in the prismatic plane, exhibits a non-planar structure. Experiments by Naka [23] on Ti single crystals, deformed in prismatic slip, have demonstrated (i) the limited mobility of screw dislocations below $500 \mathrm{~K}$, (ii) a violation of the Schmid law and (iii) a tendency towards

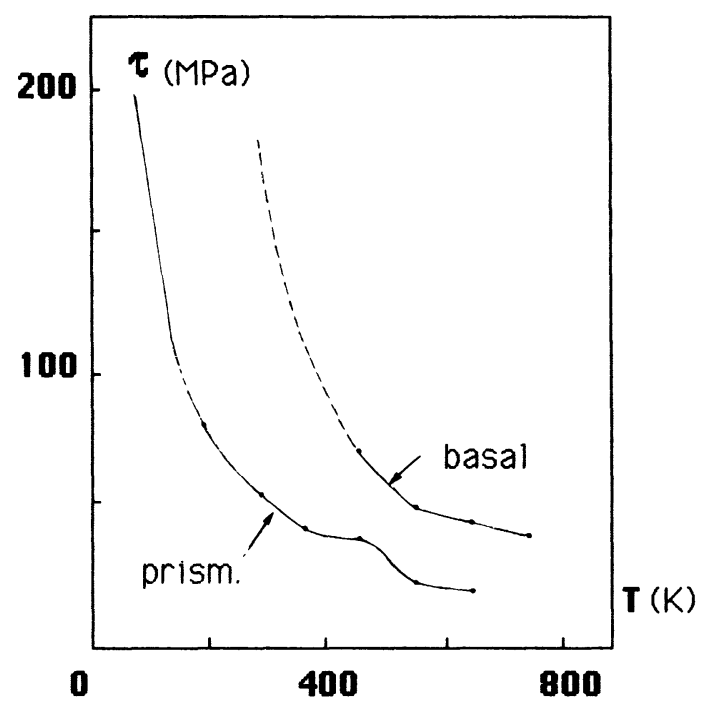

Fig. 4. - Variations of the CRSS for prismatic and basal slip in Ti (after [23]). Prismatic slip is the softest system and slip on the basal plane is thermally-activated.

cross-slip onto the first-order pyramidal system. Accordingly, Naka postulated a core structure extended onto three planes, viz. the prismatic and the two pyramidal planes in the zone of the $1 / 3<11 \overline{2} 0\rangle$ Burgers vector. This core model is essentially the same as Legrand's [22] in the sense that an additional extension off the prismatic plane is involved and that it explains the above-mentionned flow stress sensitivity to the temperature as well as the violation of the Schmid law. The atomistic simulations suggest, however, that extension occurs in the basal plane. Neither of these two core structures appears to reflect satisfactorily the observed tendency toward cross-slip on the pyramidal plane, but this may be in fact unnecessary.

4.2 NON-METALLIC CRYSTALS. - As far as non-metallic materials are concerned there is relatively little evidence of such athermal G-S core transitions 
In silicon, measurements of dislocation velocity under stress at rather low temperatures suggest that the component of the Peach-Koehler force perpendicular to the glide plane contributes to the stress exponent of the velocity [24]. According to section 2, this violation of the Schmid law would point to core effects. Despite the considerable amount of work that has been carried out so far in this field [25], there is no appropriate core model to account for the Schmid law violation and the (extrinsic) role played by point defects remains to be determined.

In gadolinium gallium garnet $\left(\mathrm{Gd}_{3} \mathrm{Ga}_{5} \mathrm{O}_{12}\right)$ deformed between $1300^{\circ} \mathrm{C}$ and $1550^{\circ} \mathrm{C}$ (melting temperature $T_{M}=1720^{\circ} \mathrm{C}$ ), a striking analogy with the low temperature plasticity of bcc metals has been pointed out [26]. The garnet structure is cubic and essentially non compact $1 / 2<111>$ is both the shortest perfect translation and the observed Burgers vector. It has been shown that either $\langle 111\rangle(112)$ or $<111 \times(110)$ is activated as the compression axis is oriented along $\langle 011\rangle$ or $\langle 001\rangle$, respectively. Since the ratio between the Schmid factors for these systems remains constant from one orientation to the other, the Schmid law is violated in this oxide. The microstructure after deformation at constant strain-rate, consists in long screw dislocations. This is explained in terms of an asymmetry of the core of screw dislocations (fig.5) in the same vein as in the model accepted for bcc metals. The same holds true for hexamine, $\left(\mathrm{CH}_{2}\right)_{6} \mathrm{~N}_{4}$, an organic crystal with Van der Waals intermolecular forces $\left(T_{M}=260^{\circ} \mathrm{C}\right)$ that exhibits the bcc symmetry [27-29].

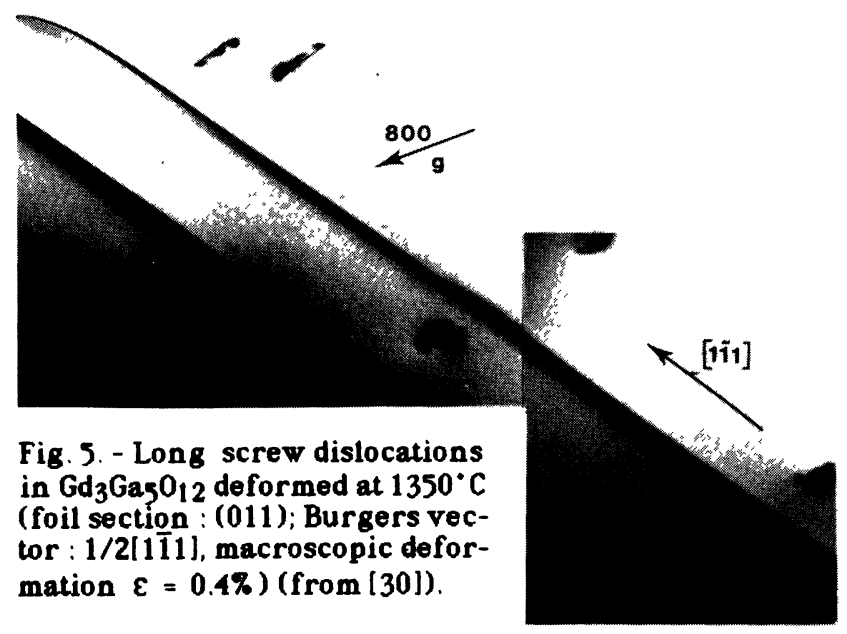

4.3 OTHER SIGNIFICANT EXAMPLES. - For the sake of completeness, the properties of glide on non-compact systems in different materials should be mentionned.

+ Experiments on $\mathrm{NaCl}$ have shown that glide could be activated on $(100)$, whereas $(110)$ is the easy glide plane ("ionic slip"). Glide on $(100)$ is strongly thermallyactivated [31]. It has been explained that, since the planes are neutral in both cases, it is the nature of the terminating atomic rows, which are charged and neutral, respectively, that is responsible for the choice of the easy glide plane. However, this is only true for the edge orientation. It has been shown experimentally that slip anisotropy is not correlated with ionic polarisability and that it is probably not the result of core spreading either (see [31-34]). In the same vein, the difficulty of activating slip on the (111) planes, which are the closepacked planes in this structure, is thought to be due to the fact they are charged (see [33-34]). By contrast, that the (111) planes are charged in the fluorine structure is invoked to explain that these are the easy glide planes in $\mathrm{CaF}_{2}[35.36]$. However, the overall situation seems to remain ambiguous since it has been pointed out by Haasen [37] that most the effects observed so far could be extrinsic in nature for they can be interpreted as the result of the (extrinsic) interaction between dislocations and a very moderate density of charged point defects.

- Glide on non-compact planes occurs in fcc metals either on $(110)$ or on $(001)$, the latter being important for subgrain migration during creep at intermediate temperatures [19]. It is agreed that the situation is not well understood and that, in many respects, it shares major analogies with prismatic slip in magnesium.

- Finally for what concerns non-compact slip, not only the slip planes but also the nature of the slip direction should be considered. Dislocations with $\langle 100\rangle$ Burgers vectors have been observed in the $\mathrm{L}_{2}$ alloys [38] despite the fact that this is the shortest perfect translation of the structure, $\langle 110\rangle$ superdislocations are systematically preferred. $\langle 100\rangle$ dislocations are formed as reaction by-products of superdislocations with orthogonal Burgers vectors, but they do not propagate, at least below $800^{\circ} \mathrm{C}$, because of highly sessile cores as reflected by their shapes (fig.6). Consistently, long $\langle 100\rangle$ dislocations are observed in the parent $\mathrm{L}_{0}$ structure but only at very high temperature ( $G$. Hug : unpublished result). The transition in slip direction that occurs at about the temperature of the flow stress peak in B2 alloys will be adressed in 55.2 (see for instance [39-41]) These effects illustrate the fact that, given the Burgers vectors, the respective mobilities of dislocations with temperature may vary dramatically.

- Worthy of mention in this section, is the plasticity below the Curie point of $\mathrm{Fe}-\mathrm{Ni}$ Invar crystals with a nickel concentration less than 45 at.\% [42-43]. In these

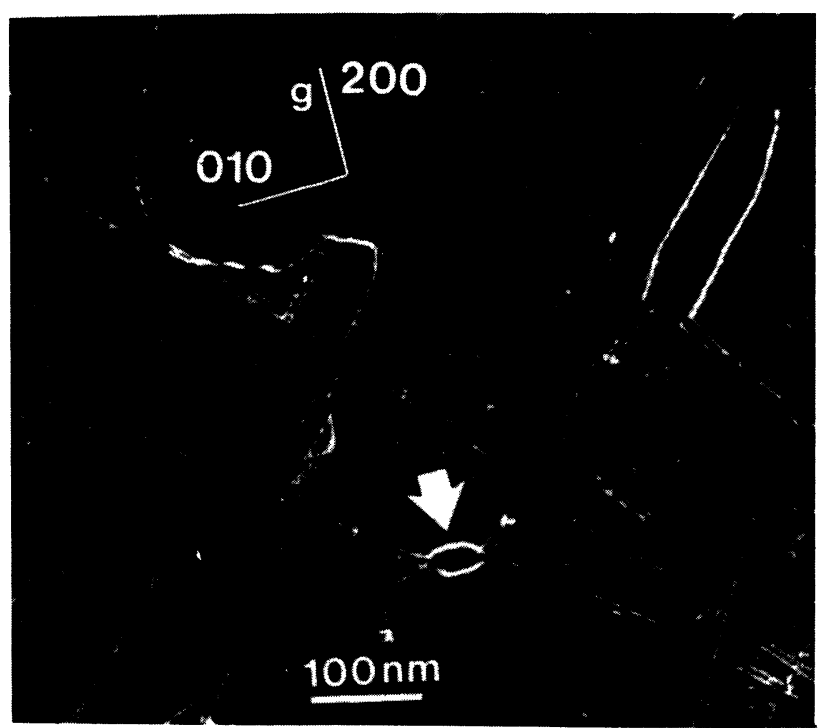

Fig. 6. - Dislocation microstructure in $\mathrm{Ni} 3 \mathrm{Al}$ deformed in compression at $650^{\circ} \mathrm{C}$. It is essentially composed of two families of dissociated screw superdislocations whose reaction gives rise to pairs of short dislocation junctions with [100] Burgers vector indicated by arrows [38]. Note the deviation of the long dissociated dislocations from the exact [011] screw orientation.

the CRSS increases much more steeply than it usually does in other concentrated fcc alloys (fig.7); the stressstrain curves are, in addition, aty pical of their fcc structure [44]. The microstructure is mostly composed of edge dislocations; screws, when present, never indicate a tendency toward locking [43]. There is good evidence for the low temperature CRSS to originate from the 


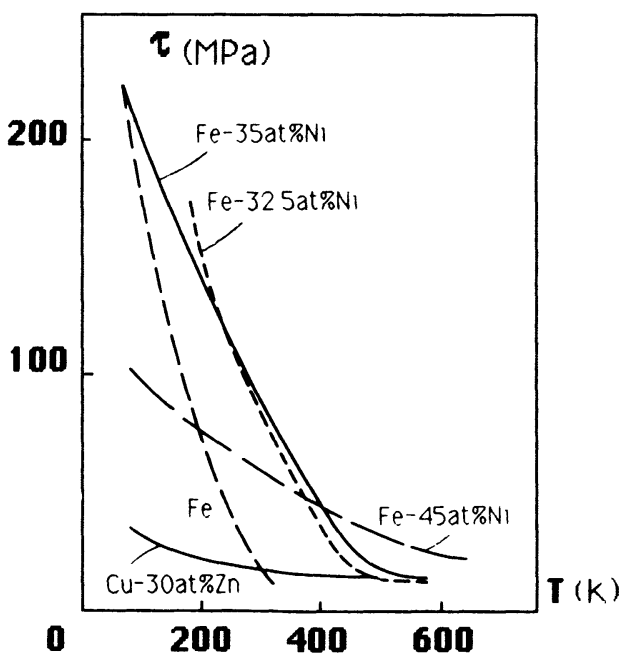

Fig. 7. - The CRSS dependence upon temperature in Fe-Ni 32.5 at.\%, 35 at.\% and 45 at.\% compared to concentrated fcc alloys and to iron which is bcc (after [42] and [43]).

magnetism of $\mathrm{Fe}-\mathrm{Ni}$ Invar through the interaction between the hydrostatic stress field of dislocations and the magnetization of the alloy. The edge-dominated microstructure reflects the dislocation character whose mobility shows the highest sensitivity to the large pressure dependence of the magnetization in Invar alloys (screws, which do not affect the hydrostatic component of the stress tensor, are insensitive to this interaction). The magnetic effects which, at the core level, cause the loss in dislocation mobility are not understood yet.

\section{Thermally-activated G-S transition.}

When the transition process from a glissile to a sessile core requires thermal energy (figure 8 ), it seems natural to consider that what controls sessile pinning is the height of the activation barrier itself; the locking conditions may however differ depending upon the glide/ climb dissociation mechanism ( 3 ), as illustrated in the following

Contrary to spontaneous spreading, the whole dislocation line with the appropriate character may not be then submitted to the transition. Instead, only a

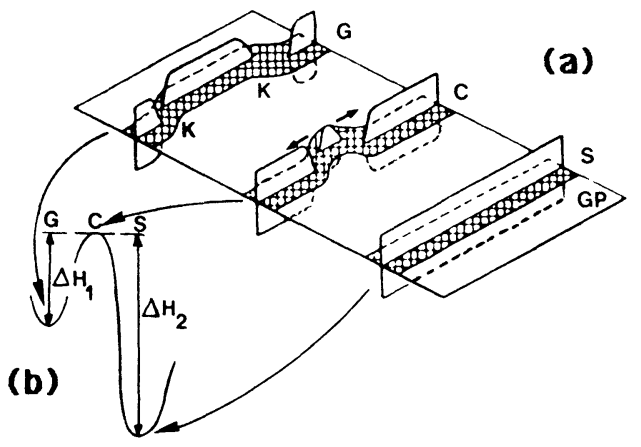

Fig. 8. - Very schematic illustration of the motion of a dislocation with a twofold core (spreading occurs partly in its glide plane (GP) and partly normal to it). a) core transition from the sessile (S) to the glissile (G) configuration which requires that a critical (C) position is surmounted before the whole dislocation line can move one atomic row by kink (K) migration. b) associated energy diagram. certain number of discrete obstacles, which contribute to pinning the dislocation, are nucleated per unit length of dislocation. Their density increases exponentially with temperature. The larger the density, the shorter the average mobile segments and the larger the stress necessary to move the dislocation. A positive response of the flow stress to temperature is then to be expected when the sessile configuration is thus achieved with the aid of thermal vibration.

Accordingly, the reverse (sessile to glissile) transition of the core may then operate by a thermallyactivated process and help unpin the dislocation. In principle, it is the competition between the nucleation rate of the pinning points and the restoration rate of the glissile core that governs the mobility of dislocations. In the instance of beryllium deformed in prismatic slip (figure 1), a substantial temperature shift between the domains where these two processes operate has been invoked in order to explain the flow stress dependence on temperature ([45-46]], see however [47-49] and S5.1).

Local deviation by cross-slip off the primary glide plane or by climb have essentially the same effect of reducing dislocation mobility. However, because the elementary processes involved are different, their activation energies, their sensitivities to stress orientation together with their respective deformation microstructures are expected to differ substantially. For instance, nucleation and restoration may not compete the same way according to the glide/climb process through which the obstacles are formed. In a climb controlled dissociation process, the locking obstacle grows spatially by repeated operation of the same elementary diffusion step (which looks actually very much like a pipe- rather than a bulk-diffusion mechanism). Dislocation mobility should then be mostly sensitive to the average distance between such obstacles. On the other hand, for a screw dislocation to adopt a sessile configuration over its entire length, only one event of nucleation of a kink pair is in principle required. Under an applied stress, further expansion of the sessile segment along the dislocation line, should then proceed almost spontaneously; this is because of the weakness of second-order Peierls forces on the deviation plane that oppose to kink migration. Under such circumstances, the temperature dependence of the flow stress should be essentially controlled by the restoration process.

So far the thermally-aided G-S transition has been described such that the driving force for obstacle nucleation is the existence of a sessile core with a lower energy than its glissile variant; it has not been determined that this must always be the case. The fact that the glissile core is the most stable configuration $\left(\Delta H_{1}>\Delta H_{2}\right.$ in figure $8 \mathrm{~b}$ ), should not prevent metastable sessile cores, if any, to be reached with the aid of thermal activation. Again, this could result in reduced dislocation mobilities according to the conditions for a backward S$\mathrm{G}$ transition.

When the G-S transition is spontaneous, the screw orientation is always favoured $(53)$. By contrast, when this transition is thermally-activated, the dominant dislocation character is not unique whatever the transition and will again depend upon the elementary process (cross-slip vs. climb) involved in order to form the eventual configuration. For example, it is the screw orientation that is of course favoured in the mechanism of local deviation by cross-slip assumed to operate in $\mathrm{L1}_{2}$ alloys at intermediate temperatures (see for example [38, $50,70])$. Alternatively, climb dissociation helps stabilize mixed dislocations in the same alloys at higher temperatures [51-52] (S 5.2)

At this stage of the analysis of core-controlled plasticity, there does not seem to exist a better classification of mechanisms than making a distinction between the thermally-aided glide and climb transitions. 5.1 THERMALLY-AIDED GLIDE G-S TRANSITION. - In order to 
explain the variations of flow stress in beryllium deformed in prismatic slip, which decreases with increasing temperature up to $170 \mathrm{~K}$ and then increases substantially with a peak at about $T_{p}=330 \mathrm{~K}$ (figure 1), Regnier and Dupouy [46] have postulated that the core of the $1 / 2\langle 1120\rangle$ screw dislocations possesses one metastable and one stable state in the prismatic and basal planes, respectively. Since the basal plane is a cross-slip plane for prismatic slip, screw dislocations are again expected to play a specific role in the rate-controlling mechanism. Below $170 \mathrm{~K}$, thermal vibrations do not help in the G-S transition, and the rapid decrease of the flow stress signals a Peierls mechanism. The fact that the slip lines are straight and often very long, attests to the operation of prismatic slip only. Between $170 \mathrm{~K}$ and $320 \mathrm{~K}$ where the "anomalous" behaviour takes place, the probability that screw dislocations transform into their basal-spread form increases with temperature. The aid of thermal activation is not, however, sufficient to promote the reverse S-G transition. Slip lines indicate, then, that both prismatic and basal planes operate at a macroscopic scale, and the higher the temperature, the more frequent cross-slip. Above $320 \mathrm{~K}$, deformation appears to be almost independent of core transitions. Again the flow stress adopts a positive dependence upon temperature and, as in bcc metals, glide is essentially non-crystallographic because of the frequency of crossslip events. In-situ weak-beam experiments have been carried out on beryllium deformed between $300 \mathrm{~K}$ and 573K [47]. Though this range of temperature is a little high to directly account for the above anomaly, invaluable information has been obtained on dislocation mobility in prismatic slip. Thin foil artefacts being eliminated by appropriately selecting the sample orientation. it is demonstrated that at about the temperature of the peak. what controls deformation is still the mobility of screws Glide occurs by a locking-unlocking mechanism which generates surface slip traces along both the prismatic and the basal planes, with no indication of the operation of pyramidal glide. Measurements of dislocation velocities show that both the pinning and unpinning mechanisms are thermally-activated. Complementary insitu observations, carried out recently below $300 \mathrm{~K}$, have shown that a flow stress peak can be again measured from local estimates of the stress that acts on individual dislocations [48]. The observed variations of the dislocation mean free path and probabilty of unlocking with temperature indicates that it is not an increase of the pinning point density with temperature but the increasing difficulty to unlock by cross-slip from basal to prismatic that may explain the flow stress anomaly [49].

Such a flow stress anomaly has also been identified during prismetic slip in some hcp alloys such as Ag2Al [53], CuGe [54] and MgIn [55]. It is worth noting that the explanation which prevails in beryllium differs from the one appropriate to these hcp crystals that deform "normally" on the prismatic system (see 54 ), in the sense that for these crystals the G-S transition is spontaneous.

Again the flow stress peaks in $\mathrm{Zn} \mathrm{[56],} \mathrm{Cd} \mathrm{[57]} \mathrm{and} \mathrm{Mg}$ $[21,58]$ when deformed in pyramidal slip. In the latter cast, there is sume indicalion, however, that dislocation blocking could be ascribed to a climb-controlled mechanism [21] ( 55.2$)$.

The anomalous flow stress dependence on temperature of Ni3Al and of a number of intermetallic alloys with the $\mathrm{L}_{2}$ ordered structure, has received wide attention over more than 25 years (see [59]). It is surprisingly lately that Takeuchi and Kuramoto [60] first postulated that the transition from the glissile to the sessile configuration, had to be thermally-activated. The resulting configuration is known as the Kear-Wilsdorf lock [61] However, nothing was known on the details of the G-S transition (figure 9) before atomistic simulations of screw dislocation cores were carried out [14]. Again, this is a posteriori a little surprising since the fully exten- ded core structure, tnat has originated from the simulations, consists in fact in the coupling of the KearWilsdorf lock and of the usual dissociation of fcc crystals (figures $3 \mathrm{~b}$ and 9 ). The $\mathrm{L}_{2}$ structure is a fcc-related ordered structure in which superdislocations possess a $<110$ Burgers vector. These are liable to dissociate into two superpartials with collinear $1 / 2\langle 110\rangle$ Burgers vectors which, in turn, may undergo the usual fcc-like splitting into $1 / 6<112>$ Shockley partials [62] represented as elongated ovals in figure 9. Below the peak temperature superdislocations glide on (111) where the fourfold configuration is wholly spread. However, because the APB energy is at a minimum on (001) planes [63] and because of the torque, due to elastic anisotropy [64], that is exerted on the superpartials out of (111), there is a driving force for local deviation of the superpartials onto the cube plane. The first step of the mechanism of local deviation ( $\alpha$ in figure 9), controls nucleation of pinning points on the leading screw superpartial (Paidar, Pope and Vitek [65]). Due to crystal symmetry, it corresponds to a spreading transition of its core from the glide plane to cross-slip plane, both of them are of (111) octahedral type. The activation energy, $\Delta H$, for the locking process comprises two terms: $\Delta H=\Delta W+\Delta U[2] . \Delta W$ is Escaig's expression of the activation energy for cross-slip between (111) planes in fcc crystals [66]; it depends on the magnitude of these stresses which affect the splitting distances in the two (111) planes of interest The second term, $\Delta \mathrm{U}$, is similar to that introduced by Takeuchi and Kuramoto [60] in order to account for the observed effects of the shear stress in the $(001)$ plane. It

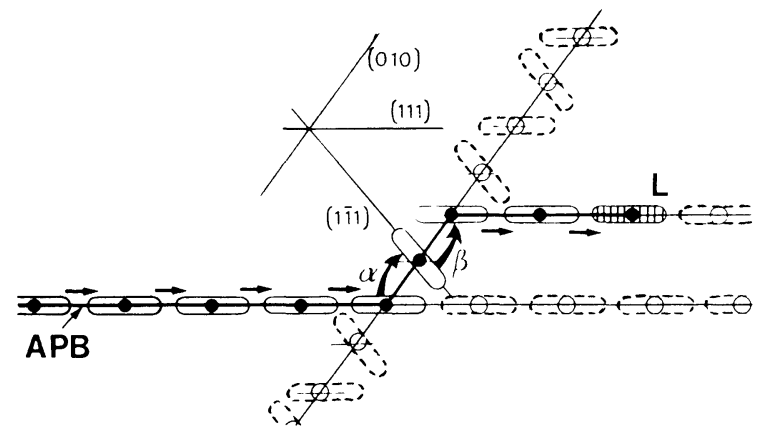

Fig. 9. - Schematic picture of the mechanism of Paidar et $* 1$. [65] for blocking of a $1 / 2[\overline{101}]$ screw superpartial in $\mathrm{L}_{2}$ alloys by local deviation. The trace of each atomic row on the (111) primary slip plane and on the $(010)$ deviation plane is represented by circles that are filled along the path of the leading superpartial (L) and open elsewhere. Similarly, the arising antiphase boundary (APB) is drawn as a thicker line. On the (010) cross-slip plane, the core adopts configurations that are alternately spread on (111) and (1i1), a property which explains the low mobility of screws on cube planes. As superpartial $L$ undergoes local deviation, it has to overcome two core transitions, $\alpha$ and $\beta$, before it can adopt a configuration which is again glissile in the (111) plane.

contains the stress applied to the superpartial in the cube plane and it should include the intrinsic driving forces for local deviation on (001). $\Delta W$ and $\Delta U$ reflect the simultaneous operation of two distinct dislocation processes that are known as the core width and the crossslip effects, respectively [67]. Excellent accord is found with the measurements of the CRSS dependence upon the orientation of the applied stress (see for instance references [2] and [59]). It should be mentioned, however, that if the deformation microstructure contains a 
large majority of screw dislocations in the temperature range of the anomaly, these are reported to be systematically dissociated and curved in the (001) plane and a deviation from the screw orientation by about $20^{\circ}$ is currently observed [69-71].

By contrast, insofar as deformation microstructures are concerned, the mechanism of local deviation of Paidar et al. [65] is best confirmed in the $L 1_{0}$ structure [16]. Similar to NizAl. TiAl exhibits an anomalous flow stress temperature dependence [72]. The dissociation schemes in $\mathrm{L}_{10}$ are analogous to those in $\mathrm{L}_{2}$, with the exception that the dissociation of the trailing $1 / 2\langle 110\rangle$ superpartial. gives rise to a superlattice intrinsic stacking fault (SISF) with low energy (figure 3c). Therefore, full cross-slip of the superdislocation on the cube plane is inhibited because the trailing (SISF) superpartial is ascribed to remain widely dissociated in the $(111)$ primary slip plane. Consistently, the $\langle 110\rangle$ superdislocations exhibit a threefold splitting, which gives rise to a SISF and an APB. At low temperature, the configuration is entirely contained in one (111) plane, with the screw orientation not systematically favoured (figure

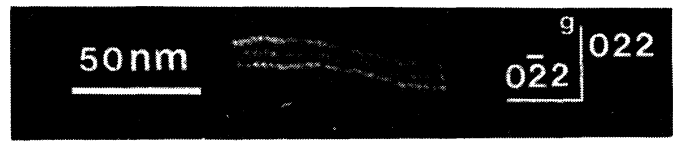

Fig. 10. - Threefold dissociation of near-edge superdislocation ( $b=[011])$, in TiAl deformed at room temperature The extended configuration is entirely contained in the (111) plane, as indicated by the alignement of the points of emergence at the specimen surface $[100,104]$.
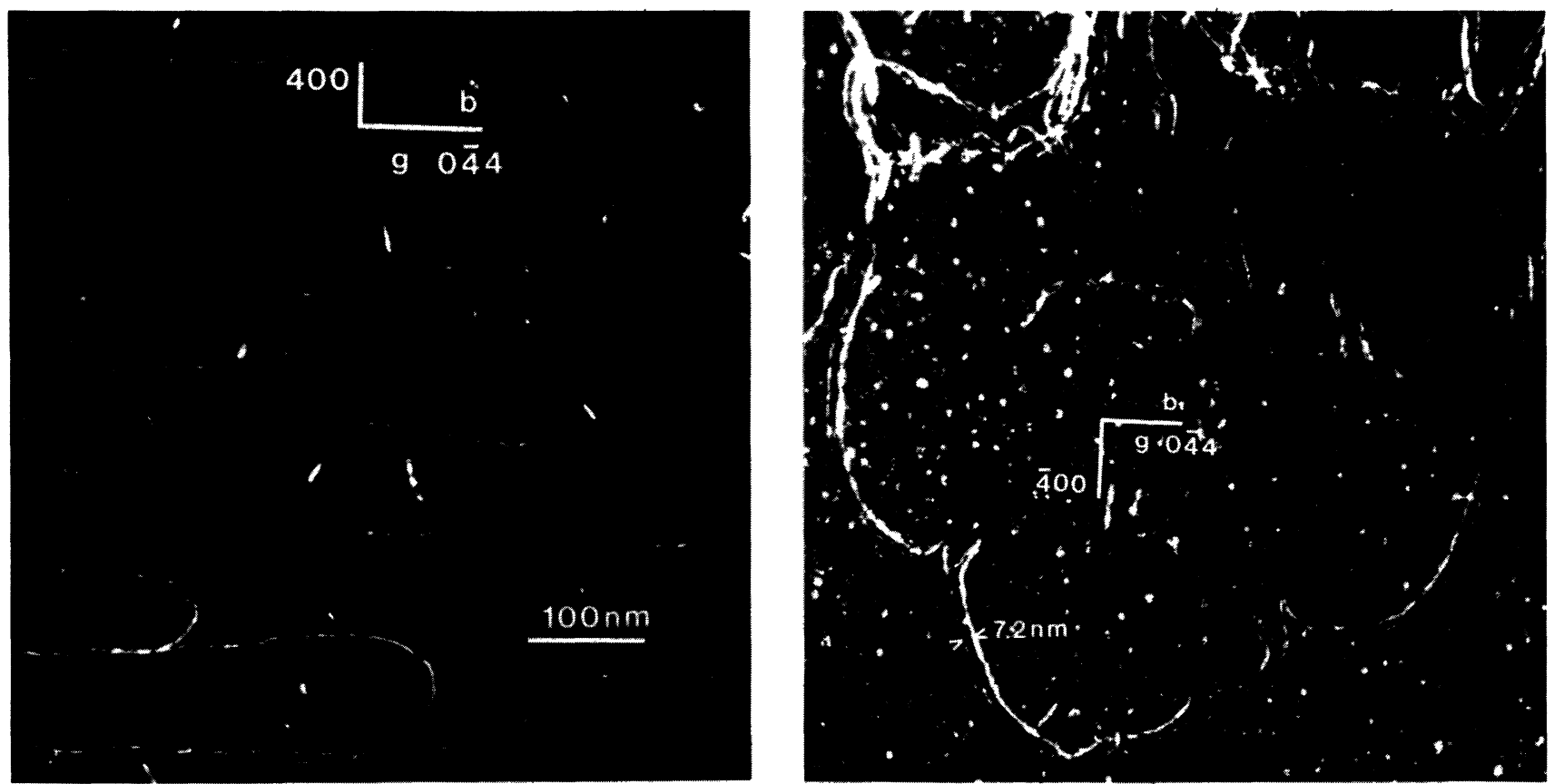

10). On the other hand, a little below the temperature of the flow stress peak, the microstructure is composed of well-defined screws with the same threefold splitting. but the APB is now stabilized on the cube plane [104].

In $\mathrm{MgAl}_{2} \mathrm{O}_{4}$ spinel, a strong thermal dependence of the CRSS together with a CRSS anomaly has been similarly found at low and intermediate temperatures, respectively, for the easy $\langle 110\rangle(110)$ glide system ([73], see figure 11 in $\$ 5.2$ ). Weak-beam observations attest to the lesser mobility of screws ([74], figure 11a), and it has been determined that the favoured glide dissociation plane is (001) (P. Veyssière and C. B. Carter 1988 : in preparation). Below the peak temperature (about $\mathrm{T}_{\mathrm{M}} / 2$ $\mathrm{T}_{\mathrm{M}}=2130^{\circ} \mathrm{C}$ ), there is, however, some indication that screws become more mobile than edges (figure 11b).

Plasticity in B2 ordered alloys is complex in particular because of the variety of slip systems that are available [2-3]. This structure is bcc-related and, at least at low temperature, $\langle 111\rangle(112)$ is the most commonly observed slip system, but there are exceptions to this rule [75]. As the deformation temperature is raised, slip on (110) along $\langle 100\rangle$ (and also $\langle 110\rangle$ ) becomes predominant; at high temperature, the $\langle 100\rangle(100)$ system has been reported in FeAl [76], the conditions for the transition from $\langle 11\rangle$ to $\langle 100\rangle$ being strongly composition dependent in this alloy [77]. In addition to the rapid decrease of flow stress at low temperature that is typical of bcc crystals, a number of $\mathrm{B} 2$ alloys show a flow stress peak at high temperature that, as in $\mathrm{L}_{2}$ alloys, coincides with the transition of slip system. The bcc-like behaviour is likely to originate from the existence of a stable sessile core of the $1 / 2<111$ > superpartials. Nevertheless, there is still much to be clarified on B2 alloys whose overall

Fig. 11. - Temperature dependence of the dislocation microstructure in spinel after low temperature deformation under hydrostatic pressure $(1.5 \mathrm{GPa})$. Both foil sections are parallel to the (011) glide plane. of the dislocations whose Burgers vector is $1 / 2[01 \overline{1}]$ in each case. a ) $400^{\circ} \mathrm{C}$. The short segments are mixed in character they have the highest mobility. The screws which appear as long but cusped dislocations are dissociated by about $2.5 \mathrm{~nm}$ in the (100) plane b ) $950^{\circ} \mathrm{C}$. The leading segment is now in nearly-screw orientation, the dissociation distance and the extension of the cusps have broadened. Note that the projections of the images of the partial dislocations intersect pointing to their motion on distinct (011) planes ( $P$. Veyssière and C.B. Carter : unpublished result). 
plastic behaviour, different from $\mathrm{L}_{2}$ alloys, does not appear as a simple modulation of the features of the parent (bcc) crystal by the ordered structure. This is presumably because the presence of the APB destroys the threefold symmetry of the 411 > screw direction $[2,3]$. Simulations suggest that the mobility of the two $1 / 2(111$, superpartials are not identical and that the trailing one is subject to cross-slip such that the two dislocations move on different planes, both dragging an APB. The dissimilarity between disordered bcc crystals and B2 ordered alloys is also manifested in the slip systems which, at low temperature, are usually $(110)$ and (112), respectively (resp. (112) and (110) at high temperature). The recent experiments by $Z$ hu and Saka [78] on $\beta$-brass have added to the complexity of the orientation dependence of the flow stress in the B2 structure. In this alloy, the violation of the Schmid law is manifested, in particular, in the asymmetry associated with the sense (tension /compression) of the applied shear. Zhu and Saka have shown that it is the sense of prestraining at room temperature that determines the temperature position $T_{p}$ of the flow stress peak.

Remarks

- As noted by Takeuchi and Kuramoto [60], a distinction should be made between dislocations submitted to a high Peierls potential, as for instance non-compact slip planes in hcp crystals, and those submitted to a locking mechanism by local deviation, as in the $\mathrm{L}_{0}$ and the $\mathrm{L}_{2}$ structures. Although dislocation motion is. controlled by the thermally-activated formation of kink pairs in both cases, they in fact differ because dislocation motion requires in the former process that a kink pair is nucleated. whereas kink pairs act, in the latter, as dragging obstacles while the remaining part of the dislocation retains a mobile core.

- crystals with $\mathrm{L1}_{2}, \mathrm{L1} 10, \mathrm{~B} 2$ tend to undergo a slip transition at about the temperature of their peak in CRSS, and this is probably true in other ordered structures,. Although this behaviour deserves further extensive investigation, it has been proven experimentally in $\mathrm{L}_{2}$ single crystals that the anomaly is still present under orientations that suppress the high temperature $<110 \times(110)$ system $[60,67,79-80]$. It is not thus ascertained that the peak is to be attributed to the transition in slip system although this is for instance postulated in $\beta$-CuZn $[40]$. Note that, more important than the peak itself, which reflects the temperature at which extensive destruction of the locks occurs, the domain of positive dependence of the CRSS upon temperature, where no slip transition occurs, remains the most intriguing question to investigate

- The concept of synchro-shear has been put forward in order to describe basal glide in the corundum structure $\left(\alpha-\mathrm{Al}_{2} \mathrm{O}_{3}\right)$ [81] ; it has also been postulated to operate in spinel, during (111) glide of dissociated dislocations [82]. In both structures, the nature of the atomic sites into which cations are located (tetrahedral vs octahedral), is varied by Shockley-type shears. In order to re-establish the correct cation occupancy within the sites defined by the oxygen sublattice, a short range motion of cations in directions (over one cationic nearest-neighbour distance) that differ from that of the dislocation partial Burgers vector may occur $[1,36]$, this is named synchro-shear. Owing to the fact that the softest slip s' stem is $<110\rangle(110)$ in spinel, this mechanism appears neither to determine the geometry of slip nor to control dislocation mobility

- When inspected at the atomic scale, as for example from atomistic simulations, cores spread out of the glide plane appear as three-dimensional distributions of atomic displacements off the regular positions. Contrary to what is assumed for synchro-shear, these displacements are a fraction of interatomic distance large. In many instances, it is unclear why dislocation motion would necessitate that their core is confined to the slip plane. Rather, especially as temperature is raised, dislocation glide operating by co-operative atomic shuffle, as in some phase transformations, could be a more relevant description.

5.2 CLIMB G-S TRANSITION. - When the available thermal energy is sufficient to facilitate atomic diffusion. dislocation climb may take place. It is worth noting that. in many respects, climb plays a role very similar to cross-slip, essentially because in both mechanisms dislocation motion off the initial glide plane is promoted. Both cross-slip and climb are usually identified as controlling recovery, i.e. an alternative deformation route is found when the obstacles met by dislocations on the primary slip system become too strong. On the other hand, under specific circumstances, a dislocation reduces its elastic energy by dissociating by climb, with adverse consequences on its further mobility. With a core extended out of the dislocation initial glide plane. the achieved climb dissociated configuration is indeed clearly sessile and, as far as slip on the primary glide plane is concerned, the similarity with a cross-slipped dislocation is again striking ( 5 )

The operation of dissociation by climb requires (i) that the perfect dislocation line delimits at least a pair of extra-half planes, (ii) that the energy of the planar defect, which would result from dissociation, favours the configuration in question and (iii) that the temperature is large enough to promote atomic exchanges between the partials [36]. Perhaps more clearly than dislocation climb, climb dissociation can be regarded as an intrinsic mechanism since, in principle, there is no need for point defects from the bulk : the vacancies that are emitted by one partial which climbs positively are absorbed by its companion which climbs negatively (figure $2 \mathrm{~b}$ ). The whole process is self-fed, and will stop when the configuration reaches its equilibrium dissociation distance [83-84]. It is promoted by the basic dislocation property according to which, given the distance between two dislocations, their interaction energy is a minimum or a maximum when the atomic plane to which they both belong, is their glide or climb plane, respectively [17]

In principle, local climb dissociation nuclei of a few atomic steps in the slip and climb directions should be sufficient in order to control dislocation mobility. This will thus be a function of the density of sessile nuclei on a per unit length basis rather than of the width of dissociation, the latter parameter being important in the unlocking process only.

Climb dissociation has first been indicated as a potential rate-controlling process by Brown [85]. The first experimental hint for its occurrence is due to Stohr and Poirier [21] who noted the predominance of edge dislocations in magnesium deformed in pyramidal slip at the temperature of the flow stress peak. Although the details of the process have not been identified clearly, there is in magnesium, consistent indication for splitting of the $\langle 1 \overline{1} 00\rangle$ edge dislocation with $1 / 3\langle 11 \overline{2} 3\rangle$ Burgers vector, into two partials in the basal plane. However, that this mechanism is rate-controlling over the whole extent of the flow stress anomaly remains unclear, since the svrew orientation dominates the microstructure in $\mathrm{Zn}$ and $\mathrm{Cd}$ where a peak is similarly observed in pyramidal slip [56-57]

Again climb dissociation has been identified in oxides with spinel [86-88], corundum [89-90] and garnet [91] structures as well as in $\mathrm{Y}_{2} \mathrm{O}_{3}$ [92]. Because of the extreme brittleness of these materials, exploring their flow stress variations at intermediate and low temperatures requires that deformation experiments be carried out under a confining pressure. This was attempted on $\mathrm{MgAl}_{2} \mathrm{O}_{4}$ $[73,93], \alpha-\mathrm{Al}_{2} \mathrm{O}_{3}[94]$ and $\mathrm{Y}_{3} \mathrm{Fe}_{5} \mathrm{O}_{12}$ and $\mathrm{Ga}_{3} \mathrm{Gd}_{5} \mathrm{O}_{12}[30,95]$. Whereas the garnet oxides do not deform plastically below $0.8 \mathrm{~T}_{M}$, it is possible to extend the domain where spinel and sapphire undergo plastic flow, down to room 
temperature (figure 12). However, insofar as a climb controlled flow stress anomaly is concerned, this led to contradictory results as pointed out in [74]. In fact the flow stress in sapphire decreases monotically with temperature whe-reas a pronounced flow stress anomaly is measured in spinel between 0.3 and $0.5 \mathrm{TM}$, but in the $\langle 110\rangle(110)$ easy glide system only ([73], s 5.1). Transmission electron microscopy indicates that, in the latter oxide, climb dissociation begins to be detectable in the vicinity of and above the temperature of the CRSS peak (figure 11b).

Owing to the striking similarity between the spinel and the ordered $\mathrm{L}_{2}$ structures in view of the crystallography of dislocation dissociation as well as of the occurrence of a flow stress anomaly, experimental evidence for climb dissociation has been looked for and pointed out in $\mathrm{L1}_{2}$ alloys [51.52] (fig. 13). However, it is not ensured that climb dissociation superimposes its effect to that of cross-slip in order to control the deformation rate below the peak temperature. What is certain is that the deformation microstructure is essentially composed of non-screw dislocations at and above the temperature of the peak and that climb dissociation events within a screw-dominated microstructure have been traced well below the peak. Recent in-situ high temperature straining experiments of $\mathrm{L}_{2}$ single crystals, deformed on cube slip have proved the rate-controlling role of climb dissociation through a locking-unlocking process [96]. Nevertheless, there is indication in Ni3Al that dislo-

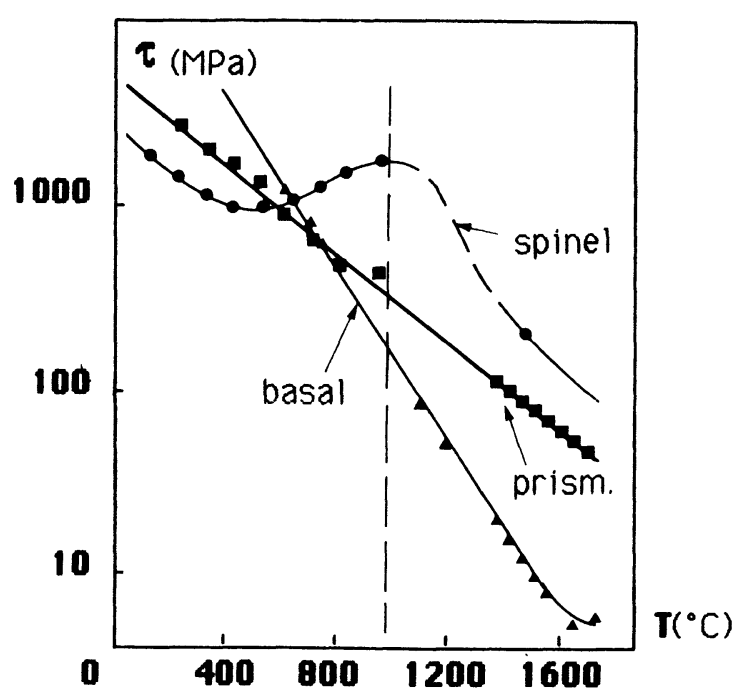

Fig. 12. - Variations of the CRSS in sapphire in basal (B) and prismatic (P) slip [94] and in spinel [73]. In the latter oxide, only the CRSS on $\langle 110\rangle(110)$, which is the softest slip system, is plotted. Below $950^{\circ} \mathrm{C}$, the experiments were carried out under a confining pressure of about $1.5 \mathrm{GPa}$ (the determination at $1530^{\circ} \mathrm{C}$ in spinel is taken from [68]).
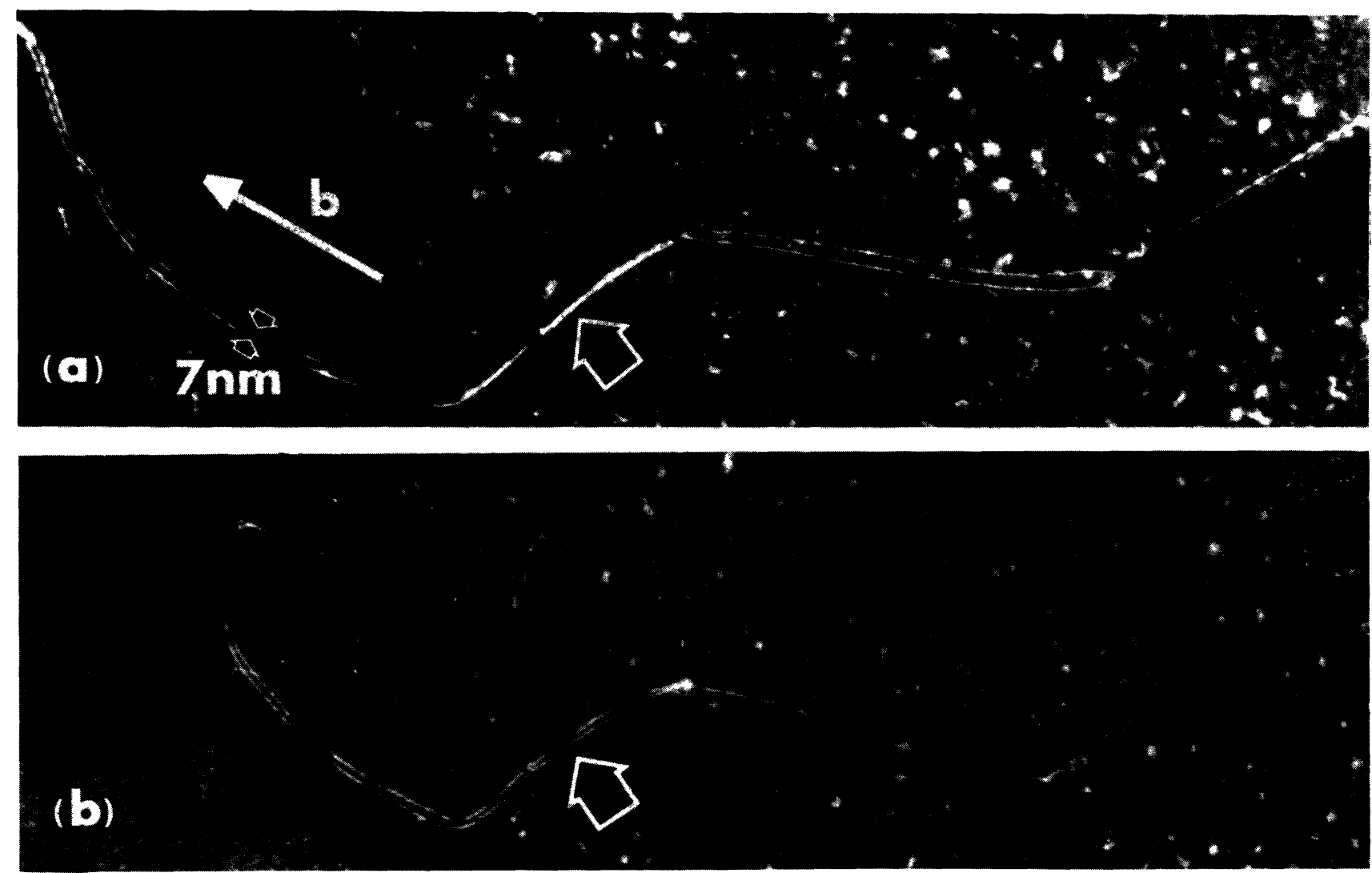

Fig. 13. - Weak-beam determination of the dissociation mode at the mixed parts of a dislocation resulting from deformation at $800^{\circ} \mathrm{C}$. The foil section is parallel to the dislocation glide plane which is (001), its total Burgers vector is $[110]$. Only the dissociation in the $(001)$ plane of the nearly-screw parts is resolved. One segment (indicated by an open arrow) exhibits a single contrast. b) Same defect after foil tilting by $45^{\circ}$ about [200], the dissociation of the near-edge segment is now clearly visible pointing to the fact that the dissociation plane of this segment does not contain its Burgers vector. From fig. 11a, it is possible to determine that this part of the superdislocation is dissociated (by climb) on the (310) plane over most of its length. 
cations may well keep gliding in their fully climb dissociated form, a process that involves APB dragging ([105], P. Caron, T. Kahn and P. Veyssière : in progress), The same feature has also been recently identified in spinel ( $P$. Veyssière and C.B. Carter : in preparation).

In nearly-stoichiometric $\mathrm{Ni}_{3} \mathrm{Si}\left(\mathrm{L}_{12}\right)$ strained $50^{\circ} \mathrm{C}$ below the temperature of the peak, the microstructure is dramatically varied according to whether deformation is followed by slow or fast cooling [97] (figure 14). A slow cooling rate is the experimental procedure that is usually adopted for $\mathrm{L}_{2}$ alloys; in this case the microstructure consists of mixed superdislocations, that are fully dissociated by climb, with a dominant nearedge character (figure 14a), climb dissociated nearscrews are also encountered. By contrast, the quenched samples exhibit a large density of near-edge superdislocations that are dissociated in their glide plane (figure 14b). Nevertheless, they exhibit a number of local pinning events that are not located in register on both superpartials. At these points and from either superpartials, narrow mixed dipoles may originate. hence providing traces of dislocation motion that are distinct for each superpartial. Further work is evidently needed in this direction on a number of $\mathrm{L}_{2}$ alloys, but the presence of mixed dislocations as a typical microstructural feature in $\mathrm{Ni} 3 \mathrm{Si}$, quenched immediately after deformation, supports the view that climb events contribute to control plastic deformation below the temperature of the peak.

Evidence of climb dissociation has been reported in $\beta$ brass deformed at the temperature of the flow stress peak by Saka and $\mathrm{Zhu}$ [98] and preliminary experiments in TizAl, which has the hcp-related D019 ordered structure, have revealed the same feature [99].
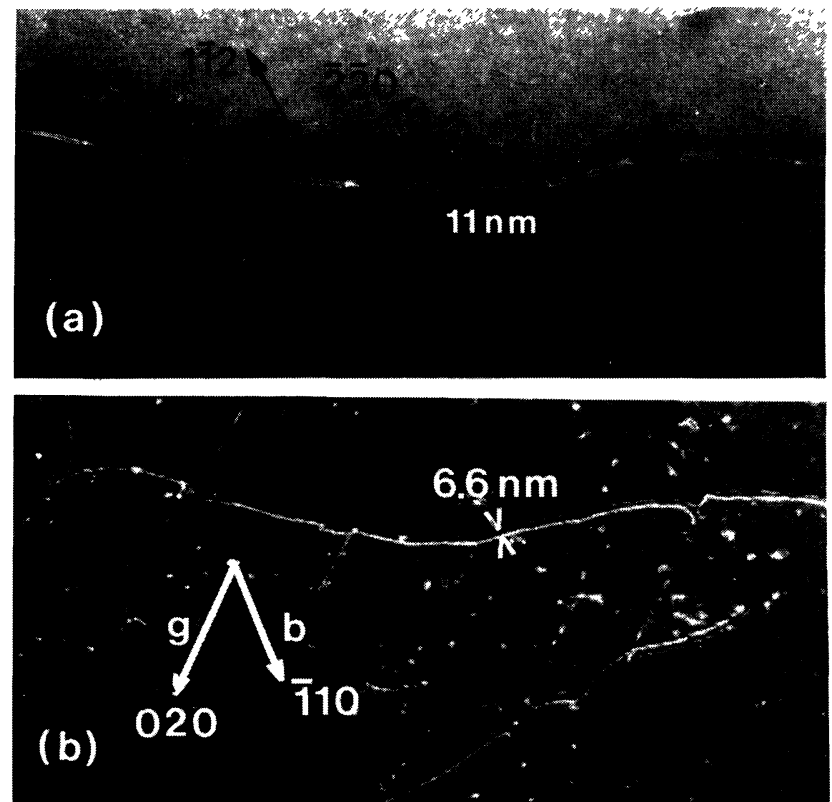

Fig. 14. - Comparison between the dislocation fine structures in nearly-stoichiometric $\mathrm{Ni}_{3} \mathrm{Si}$ deformed $50^{\circ} \mathrm{C}$ below the temperature of the flow stress peak. a) annealed sample b) quenched sample. (B. Tounsi and P. Veyssière : unpublished result)

Remarks :

- It is worthy of mention that climb dissociation appears to be a rather general splitting mode in ordered intermetallic alloys. To the author's knowledge. TiAl $(\mathrm{L} 10)$ is the only instance within this category of materials where, whatever the deformation temperature below $1000^{\circ} \mathrm{C}$, attempts at pointing out diffusive dissociation have remained totally unsuccessful [100].

- On the other hand, note that, with the exception of $\alpha$ $\mathrm{Al}_{2} \mathrm{O}_{3}$, a flow stress anomaly has been reported to occur in every material that exhibits dislocations dissociated by climb. However, in neither case has this mechanism proved so far to be a better candidate than cross-slip in order to explain the anomaly.

- The TEM observations have not completely established the view that the flow stress is a consequence of dislocation locking by glide deviation and this is because of the existence of the flow stress peak itself. Indeed. as soon as the stress which is reached at the end of the deformation test is larger than the flow stress at room temperature (at which the observations are carried out), there is a driving force for potential microstructural reorganization after which most of the dislocations that have moved, should exhibit configurations specific to deformation at lower temperatures. This could explain the sudden change in deformation microstructure observed which occurs in $\mathrm{L}_{2}$ crystals at about the peak temperature.

\section{Strain-rate sensivity.}

Given a range of temperature where deformation is governed by one single thermally-activated mechanism yielding a regular decrease of the flow stress $\sigma_{e}$, the strain-rate sensitivity $s$ of the flow stress :

$$
s=\left(\partial \sigma_{e} / \partial \ln \dot{\varepsilon}\right)_{T}
$$

reaches a peak value when plotted against temperature (figure 15a). Indeed, if the flow stress variation obeys an Arrhenius law, it is equivalent to refer to the activation area, $\Sigma$, of the process which is simply related to $s$ by

$$
s=k T / b \Sigma \text {. }
$$

The activation area characterizes some surface swept by a dislocation line as it overcomes the rate-controlling obstacle. Since the activation enthalpy verifies

$$
\Delta \mathrm{H}=-\mathrm{b} \Sigma \mathrm{T}\left(\partial \sigma_{\mathrm{e}} / \partial \mathrm{T}\right)_{\dot{\varepsilon}}
$$

and should be proportional to $T(\Delta H=\lambda \mathrm{kT}$, with $\lambda$ of the order of 25 to 35 ), one gets

$$
\Sigma=-\alpha\left[1 /\left(\partial \sigma_{e} / \partial \mathrm{T}\right)_{\varepsilon}\right]
$$

where $\alpha$ is a proportionality factor. Hence, $\Sigma$ increases monotonously with temperature (or decreases with $\sigma_{e}$ ), and takes very large values at the athermal plateau.

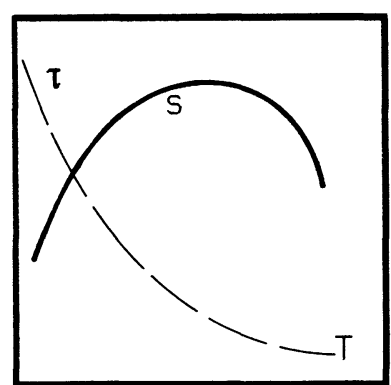

(a)

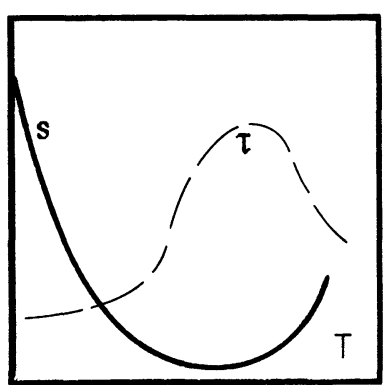

(b)
Fig. 15. - Variations of the CRSS sensitivity to the deformation-rate, s, when the flow stress : $a$ ) undergoes a thermally-activated decrease. b) exhibits an anomalous peak.

In general, the above formalism approximates rather 
closely the deformation mechanisms that have been adressed in 54 , i.e. when the dislocation core is spontaneously sessile (figure 15a). On the other hand. flow stress peaks seem to go along with a dramatic drop of s (figures 15b), whose explanation is unclear. So far the only model to account for this behaviour has been put forward by Takeuchi and Kuramoto [60] for $\mathrm{L}_{2}$ alloys. It is based on a description of the drift velocity of dislocations through a distribution of obstacles. In this dynamical break-away process, forming and breaking the dragging portions result in a steady-state distribution of sessile obstacles on the dislocation line. There remains difficulties, however, because the absence of strain-ageing effects, which is experimentally observed in $\mathrm{L}_{2}$ alloys [101], has never been accounted for. This last macroscopic property, which remains poorly documented, is itself rather puzzling since it seems to be inconsistent with the view of a thermally-activated nucleation of sessile point-like obstacles on the dislocation line.

The anomalous behaviour of $s$ (figure $15 \mathrm{~b}$ ) is also reflected through an alternative engineering definition of the flow stress sensitivity to the strain-rate, $s^{*}$ :

$$
s^{*}=(1 / T)\left(\partial \ln \sigma_{e} / \partial \ln \dot{\varepsilon}\right)_{T}=\left(1 / \sigma_{e} T\right) s
$$

which, again, almost vanishes in the domain of temperature where the flow stress peaks. For instance, $s^{*}$ is a minimum in $\mathrm{TiAl}$ [72] and $\mathrm{Ni3} \mathrm{Al}$ [102], but this may largely be due to the very definition of $s^{*}$.

Under similar circumstances, a divergence of the activation volume (proportional to $\mathrm{T} / \mathrm{s}$ ), over the range of temperature where the flow stress peaks, is reported (see for instance $[23,47]$ ). It is in fact coupled with a failure of the above formalism because some of the assumptions involved happen to be no longer valid. This fialure may arise, for example, from the competition between two or more mechanisms. It may also result from the fact that the density of obstacles, per unit length of dislocation, increases with temperature, and that, as a consequence, the preexponential term in the Arrhenius law cannot be considered as constant.

Further contributions are needed in this field, both from the experimental and theoretical points of views.

\section{Summary and conclusions.}

In a number of instances the flow stress dependence upon temperature and orientation can be unambiguously related to properties that are intrinsic to dislocations as opposed, for example, to interactions with point defects or impurities, changes in order parameter etc... The variety of crystalline materials, covered in this review, points to the fact that plasticity is generally dictated by core effects $i$. e. these changes in dislocation mobility which result from a core at least partially spread out of the dislocation primary glide plane. When the core is entirely confined to this plane and atomic bonds are metallic in nature, i.e. neither directional nor too strong, the CRSS is orientation and temperature insensitive, as in fcc and some hcp metals and alloys (figure 16a).

There are two alternative spreading modes depending upon whether spreading has occurred by glide or by climb (figure 16) and both are observed in many different systems. They can be regarded as blocking mechanisms resulting from local deviation, however because the elementary dislocation processes involved are different, their activation energies, their sensitivities to stress orientation together with their respective deformation microstructures are expected to differ substantially.

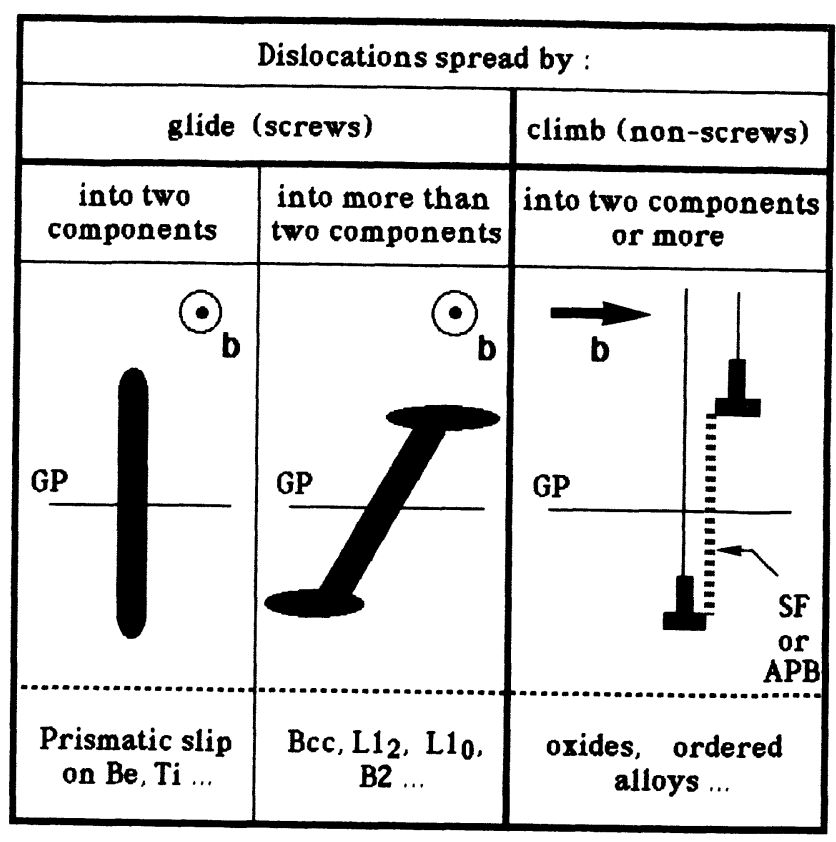

Fig. 16. - Schematic presentation of the different cases which yield core configurations that are sessile in the dislocation glide plane (GP).

As far as the deformation microstructure is concerned, what signals the role played by each process is the dominant dislocation character : cross-slip and climb controlled microstructures corresponding in principle to a dominant density of long screws and long near-edges, respectively.

Core-controlled plasticity is signaled (i) by some changes occurring in the CRSS value, at a given temperature, when the orientation of the applied stress is varied (deviation from Schmid law) together with (ii) a pro-

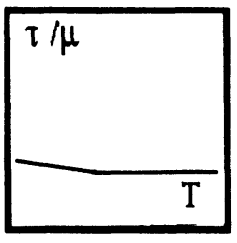

ex : fcc metals, hcp on basal plane.

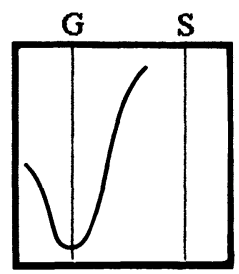

(a)

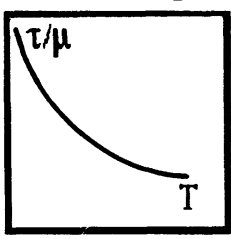

ex : bcc, prism., Te, S, Si, Pt 3 Al, garnet.

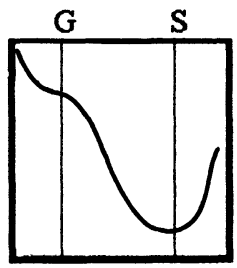

(b)

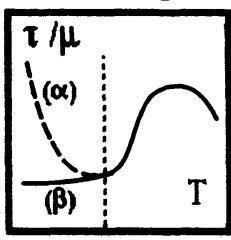

ex :

$(\alpha)$ Be, spinel

( $\beta$ ) $\mathrm{B} 2, \mathrm{~L}_{2}, \mathrm{~L}_{1}$

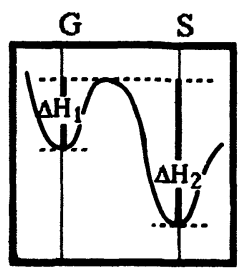

(c)
Fig. 17. - Schematic view of the distinct dependences of the CRSS upon temperature that can be found in crystals and the corresponding dislocation energy diagrams. a) the glissile core is the only stable configuration and the CRSS is temperature insensitive. b) the sessile core is stable and there is no metastable glissile core : the CRSS shows a pronounced negative sensitivity to temperature. c) there are two metastable cores and two different CRSS regimes depending upon the nature of the stable core at low temperature $(\alpha)$ glissile core, $(\beta)$ sessile core ; in both cases, the CRSS reaches a peak value at intermediate temperature. 
nounced (negative and/or posititive) dependence upon temperature (figures $17 \mathrm{~b}$ and $17 \mathrm{c}$ ). The situation where the CRSS decreases monotonously with temperature is believed to reflect the existence of a single and sessile stable core configuration (figure 17b). Nevertheless, a dislocation can possess several metastable core structures and this gives rise to specific signatures on the curves as for instance the so-called anomalous peak in temperature (figure $17 \mathrm{c}$ ). In the latter case, two alternative behaviours can be obtained additionally at low temperature : depending upon whether the low temperature core is glissile or sessile, the CRSS will exhibit a shape similar to those plotted in figures $17 \mathrm{a}$ and $17 b$, respectively. Such cases have been observed. For instance, curve $(\alpha)$ in figure $17 \mathrm{c}$ is typical of beryllium deformed in prismatic slip as well as of spinel deformed below $0.5 \mathrm{~T}_{M}$, whereas curve $(\beta)$ has been reported for most $\mathrm{L}_{2}$ alloys. A few $\mathrm{L}_{2}$ alloys, however, behave as in figure $17 \mathrm{~b}$ as if there was no stable glissile core at low temperature $[2,103]$.

Regarding the scope of this conference, and as a conclusion, it seems to be worth emphasizing that dislocation effects, even limited to what concerns the very first steps of permanent straining, can be rather complex. Although they had better be, dislocations are not (always) trivial objects that can be readily ignored for mechanistic modeling purposes.

\section{Acknovlodgenonts.}

The contribution of $B$. Tounsi as well as fruitful discussions with Drs. S. Naka, B. Legrand, A. Couret, D. Caillard, B. Escaig and M. P. Puls are gratefully acknowledged.

\section{References}

(1) Escalg, B I Phys Collog 35 (1974) C7-151.

[2] VITEK, V., Dislocations and Propertios of Real Materials, edited by the Physical Society (Arrowsmith, Bristol) 1985, p.30.

[3] DUESBERY, M.S., Dislocations in Solids edited by F.R.N. Nabarro, in the press

[4] BEAUCHAMP, P., and RABIER, J., Dislocations 1981, edited by P. Veyssière, L.P. Kubin and J. Castaing (CNRS, Paris) 1984, p. 111.

[5] PULS, M.P., and W00, C.H., Dislocations 1981, edited by P. Veyssiere, L.P. Kub in and J. Castaing (CNRS, Paris) 1984, p. 93

[6] PULS, M.P., Dislocation Modelling in Physical Syscems, edited by J.P. Hirth et al. (Pergamon Press, Oxford), p. 249

[7] ChRISTIAN, J.W., Metall. Trans. 14 A (1983) 1237

18] EsNOUF, C., Dislocations 1981, edited by P. Veyssière, L.P. Kubin and J. Castaing (CNRS, Paris) 1984, p 179.

[9] SUZUKI, T., SKrotSki, W., and HAASEN, P., Phys. Stat. Sol. (b) 103 (1981) 763

[10] Skrotski, W., and HAASEN, P., J. Phys. Colloq. 42 (1981) C3-119.

[11] HAASEN, P., BARTHEL, C., and SUZUKI, T., Dislocations in Solids, edited by $\mathrm{H}$. Suzuki et al. (Univ. of Tokyo Press) 1985, p.455.

[12] VITEK, V., Phil. Mag. 18 (1968) 773 ; Crystal Lattice Defects 5 (1974) 1

[13] HIRSCH, P.B., 5th Iat. Conf. Crystallography, Cambridge (oral communication) (1960) p. 139.

[14] YAMAGUCHI, M., PAIDAR, V., POPE, and VITEK, V. Phil. Mag. A 45 (1982) 867.

15] Greenberg, B.A., Phys. Stat. Sol. 42 (1970) 459 ; ibid. (b) 55 (1973) 59

[16] HUG, G., LOISEAU, A., and VEYSSIERE, P., J. Electron. Micr. Suppl. 35 (1986) 1575

[17] HIRTH, J.P., and LOTHE, J., Theory of Dislocations, 2nd edition (J. Wiley and Sons, New. York) (1982)

[18] DI PERSIO, J., ESCAIG, B., HAMPTON, E.M., SHERWOOD, J.N., Phil. Mag. 29 (1974) 733 ; ibid. 743.

[19] BONNEVILLE, J., CAILLARD, D., CARRARD, M., and MARTIN, J.L., Mechanisms and Mechanics of Plasticity, edited by J. Castaing, J.L. Strudel and A Zaoui (Editions de Physique, Orsay) this volume.
[20̈] SESTAK, B., Strength of Metals and Alloys, ICSMA5, edited by P. Haasen, V. Gerold and G. Kostorz (Pergamon Press, Oxford) 1979, p.1461.

[21] STOHR, J.F., and PoIRIER, J.P., Phil. Mag, 25 (1972) 1313.

[22] LEGRAND, B., These de Doctorat Orsay (1984); Dislocations 1981 edited by P. Veyssière, L.P. Kubin and J. Castaing (CNRS, Paris) 1984, p. 73 ; Phil Mag. B 49 (1984) 171; Phil. Mag. A 54 (1986) L43

[23] NAKA, S., These de Doctorat, Orsay (1983)

[24] ALEXANDER, H., Dislocations 1981, edited by P. Veyssière, L.P. Kubin and J. Castaing (CNRS Paris) 1984, p. 283; KISIELOWSKI-KEMMERICH, C. and ALEXANDER, H., Sth Int. Symposium on "Structure and Dislocations in Semiconductors" Moscow (Izvestiya Akademii Nauk Fizicheskaya Seriya) 1986

[25] HEGGIE, M.I., Dislocations 1981, edited by P. Veyssière, L.P. Kubin and J. Castaing (CNRS, Paris) 1984, p. 305

126] RABIER, J., and GAREM. H., Mater. Sci. Research, 18 (1984), Deformation of Ceramic Matorials II, edited by R.E. Tressler and R.C. Bradt (Plenum Press : New York), p. 187.

[27] DI PERsio, J., and EsCaig, B., Phys. Stat. Sol. 40 (1977 $393 ; J$. Physique Collog. 39 (1978) C2-68 Dislocations 1984 edited by P. Veyssière, L.P. Kubin and J. Castaing (CNRS, Paris) 1984, p. 267.

[28] DI PERSIO, J., These de Doctorat, Lille (1980).

[29] VANDERSCHAEVE, G., and ESCAIG, B., Dislocations et Deformation Plastique, edited by P. Groh, L.P. Kubin and J.L. Martin (Editions de Physique Paris) 1980, p.141

[30] GAREM, H., These de 3eme Cycle, Poitiers (1983).

[31] SKROTZKI, W., and HAASEN, P., J. Phys. Colloq. 42 (1981) C3-119.

[32] PHILIBERT, J., Mater. Sci. Monographs 20 (1984) 251 ( The Structure and Properties of Crystal Defects edited by V. Paidar and L. Lejcek, Elsevier Amsterdam) ; Basic Properties of Binary Oxides edited by $A$. Dominguez Rodriguez, J. Castaing and R. Marquez (Publicaciones de la Universidad de Sevilla) 1984, p. 279. 
[33] PULS, M. P., Mater. Sci. Monographs 20 (1984) 282 ( The Structure and Properties of Crystal Defects edited by V. Paidar and L. Lejcek, Elsevier: Amsterdam).

[34] Castaing, J., J. Phys. Collog. 11 (1979) C7-127; Annales Phys. 6 (1981) 195.

[35] Evans, A.G., and PratT, P.L., Phil. Mag. 20 (1969) 1213.

[36] BRETHEAU, T., CASTAING, J., RABIER, J., and Veyssiere, P., Adv. Phys. 28 (1979) 835.

[37] haAsen, P.. J. Phys. Collog. 34 (1973) C9-205.

[38] VEYSSIERE, P., and DOUIN, J., Phil. Mag. 51 (1984) L1.

[39] SaKa, H., KawaSe, M., Phil. Mag. 49 (1984) 525

[40] Saka, H., ZhU, Y.M., KaWASe, M., Phil. Mag. 51 (1985) 525

[41] Yamaguchi, M., Umakoshi, Y., Phil. Mag. 39 (1979) 33.

142] FLOR, H., GUDLADT, H.J., and SCHWINK, CH., Acta Met. 28 (1980) 1611

[43] Retat, I., Steffens, Th., and SCHWink, CH., Phys Stat. Sol. 92 (1985) 507

[44] SESTAK, B., and SEEGER, A., Z. Metallt. 69 (1978) 195; ibid. 395 ; ibid. 425.

[45] REGNIER, P., Thesse de Doctorat, Orsay (1969).

[46] REGNIER, P., and DUPOUY, J.M., Phys. Stat. Sol. 23 (1967) K109; ibid. 39 (1970) 79.

[47] CourET, A.,Thesse de Doctorat, Toulouse (1985).

[48] Couret, A., and CAILlaRD, D., in Riso Conf., (1987).

[49] CoURET, A., and CAILLARD, D., Mechanisms and Mechanics of Plasticity, edited by J. Castaing, J.L. Strudel and A. Zaoui (Editions de Physique, Orsay) this volume.

[50] Staton-bevan, A., and Rawlings, R.D., Phil. Mag. 32 (1975) 787.

[51] VeYssiere, P., GUAN, D.L., and RABIER, J., Phil. Mag. A 49 (1984) 45

152] VEYSSIERE, P., Phil. Mag. A 50 (1984) 189

[53] MOTE, J.D., TANAKA, K., and DORN, J.E., Trans. Met. Soc. A.I.M.E. 221 (1961) 858

[54] THORNTON, P.H., Acta Met. 14 (1966) 1257

[55] BACH, P., These do Doctour Ingeniour, Nancy, (1969).

[56] Blish, R.C., and VReEland, T. Jr., J. Appl. Phys. 40 (1969) 884.

[57] PRICE, P.B., Electron Microscopy and the Strength of Crystals edited by G. Thomas and J. Washburn (Interscience : New York) 1963, p. 41

[58] STOHR, J.F., These de Doctorat, Orsay (1972).

[59] POPE, D.P., and EzZ, S.S., Int, Metall. Rev. 29 (1984) 136

[60] TAKEUCHI, S., and KURAMOTO, E., Acta Mot. 21 (1973) 415

[61] KEAR, B.H., and WILSDORF, H.G.F., Traas. Met. Soc. A.I.M.E. 224 (1962) 382.

[62] COPLEY, S.M., and KEAR, B.H., Trans Met. Soc. A.I.M.E. 239 (1967) 977.

[63] FLINN, P.A., Traas. Met. Soc. A.I.M.E. 218 (1960) 145

[64] YOO, M.H., Scripta Mot. 20 (1986) 915.

[65] PAIDAR, V., POPE, and VITEK, V., Acta Met. 32 (1984) 435

[66] Escaig, B., J. Phys. 29 (1968) 225 ; Dislocation Dyaamics, edited by A.R. Rosenfield, G. T. Hahn, A. L. Bement Jr, and R.I. Jaffee (McGraw Hill NewYork) 1968, p. 665 .

[67] POPE, D.P. and VITEK, V. Dislocations in Solids edited by $H$. Suzuki, T. Ninimiya, $K$. Sumino and $S$ Takeuchi (Univesity of Tokyo Press : Tokyo) 1985 p. 67 ; Mater. Sci. Monographs 20 (1984) 37 ( The Structure and Propertios of Crystal Dofects edited by V. Paidar and L. Lejcek, Elsevier: Amsterdam).
[68] DUCLOS, R., These de Doctorat, Lille (1980).

[69] Veyssiere, P., DOUIN, J., and BeauChamp, P., Phil Mag. A 51 (1985) 449

[70] Douin, J., Beauchamp, P., and Veyssiere, P., Phil Mag. A 54 (1986) 375.

[71] DouIN, J., These de Doctorat Poitiers (1987).

[72] KAWABATA, T., KANAI, T., and IZUMI, 0., Acta Met. 33 (1985) 1355.

[73] VeYSSIERE, P., KIRBY, S.H., and RABIER, J., J. Physique Collog. $41(1980) \mathrm{C} 6-115$

174] Veyssiere, P... and CASTAING, J., Proc. of the E.M.S.A. M.A.S. Meeting (Albuquerque, USA, 1986)

[75] YAMAGUCHI, Y., UMAKOSHI, Y., and YAMANE, T., Scripta Met. 16 (1982) 607

[76] UMakOSHI, Y., and Yamaguchi, Y., Phil. Mag. A 11 (1980) 573

[77] Umakoshi, Y., and Yamaguchi, Y., Phil. Mag. A 44 (1981) 711 .

[78] ZHU, Y.M., and SAKA, H., Phil. Mag. A 54 (1985) 783.

[79] PAK, H., SABURI, T., and NENNO, S., Trans. Jap. Inst. Met. 18 (1977) 617

[80] UMAKOSHI, Y., POPE, D.P., and VITEK, V., Acta Met. 32 (1984) 449

[81] KRONBERG, M.L., Acta Met. 5 (1957) 507

[82] HoRnstra, J., J. Phys. Chem. Sol. 15 (1960) 311

[83] VEYSSIERE, P.. Rad. Effects 74 (1983) 1.

[84] VEYSSIERE, P., RABIER, J., GAREM, H., and GRILHE, J., Phil. Mag. A 38 (1978) 61

[85] BROWN. N.. Phil. Mag. 4 (1959) 693.

[86] VEYSSIERE, P., RABIER, J., GAREM, H., and GRILHE, J., Phil. Mag. A 33 (1976) 143.

[87] DONLON, W.T., Mitchell, T.E., and Heuer, A.H., Phil Mag. A 40 (1979) 351.

188] DOUKHAN, N., and DOUKHAN, J.C., J. Micr, Spectr Electr. 3 (1978) 285.

[89] PhILlIPS, D.P., MITCHELl, T.E., and HeUER, A.H., Phil Mag. 45 (1982) 371

[90] PHILliPS, D.P.,and CAD0Z, J., Phil. Mag. 46 (1982) 583.

[91] RABIER, J., VEYSSIERE, P., GAREM, H, and GRILHE, J. Phil. Mag. 39 (1979) 693 ; RABIER, J., VEYSSIERE P., and GAREM, H., Phil. Mag. 41 (1981) 1363.

[92] Gaboriaud, R.J., Phil. Mag. A 44 (1981) 561

[93] KIRBY, S.H., and VeYsSiERE, P., Phil. Mag. A 41 (1980) 129.

[94] Castaing, J., CAd0Z, J., and KIRBY, S.H., J. Phys. Collog. 42 (1981) C3-43.

[95] Garem, H., Rabier, J,, and KIrby, S.H., Phil. Mag. A 51 (1985) 485.

[96] Clement, N., CAIllard, D., Beneteau, A., and Cou jou A. in Riso Conference (1987).

[97] TouNSI, B., These de Doctorat, Poitiers (1988)

[98] SAKA, H., and ZHU, Y.M., Phil. Mag. A 51 (1985) 629.

[99] THOMAS, M., VASSEL, A., and VEYSSIERE, P., Scripta Met. 21 (1987) 501.

[100] HUG, G., These de Doctorat, Orsay (1988)

[101] DAviES, R.G., and STOLOFF, K., Trans. Met. Soc. A.I.M.E. $233(1965) 714$

[102] THORNTON, P.H., DAVIES, R.G., and JOHNSTON, T.L. Met. Trans. 1 (1970) 207.

[103] WEE, D.M., POPE, D.P., and VITEK, V., Acta Met. 32 (1984) 829

[104] Hug, G., Loiseau, A., and Veyssiere, P., Phil. Mag. A (1988) in the press.

[105] VEYSSIERE, P., HORTON, J.A., YOO, M.H., and LIU, C.T. Phil. Mag. Letters (1988) in the press 